\title{
Migration of breast cancer cells into reconstituted type I collagen gels assessed via a combination of frozen sectioning and azan staining
}

\author{
Kyohei Fukuda, Yo Kamoshida, Taisuke Kurokawa, Mioto Yoshida, Yoko Fujita-Yamaguchi*, \\ Munehiro Nakata**
}

Department of Applied Biochemistry, Tokai University, Hiratsuka, Kanagawa, Japan.

\begin{abstract}
Summary This study sought to devise a way to assess the infiltration of cancer cells in model stromal tissues. Human breast carcinoma MDA-MB-231 cells were loaded on the surface of a type I collagen gel in the well of 8-well chamber slide and allowed to migrate into the gel. The gel was then subjected to frozen sectioning and staining. Azan staining facilitated satisfactory microscopic observation of cancer cells migrating into the collagen gel. Cell migration was promoted by the presence of fetal calf serum in the gel. In contrast, the proportion of cells remaining on the gel surface increased in the presence of galardin, a matrix metalloproteinase inhibitor. Moreover, the distance of cell migration from the gel surface was significantly shorter depending on the concentration of galardin. Observation of cancer cell migration into reconstituted type I collagen gel with a combination of frozen sectioning and azan staining is a useful way to assess the ability of individual cancer cells to migrate and to evaluate how effectively pharmaceuticals inhibit the first step of invasion.
\end{abstract}

Keywords: Cancer cell invasion, type I collagen, frozen section, azan stain, galardin

\section{Introduction}

Cancer cells that develop in epithelial tissues destroy the basement membrane and invade stromal tissues $(1,2)$. During invasion, some matrix metalloproteinases (MMPs) are involved in the degradation of extracellular matrix components such as type IV collagen in the basement membrane and type I collagen in stromal tissues $(3,4)$. Since cancer cell invasion is an initial stage of metastasis, the ability to observe and control that invasion would benefit cancer research.

A Boyden chamber assay is typically used to assess cancer cell invasion by comparing the number of cells on a gel surface to the number that reach the bottom of the gel (5-7). This method is convenient but it does not allow the detailed observation of the invasive characteristics of individual cancer cells. A previous study used time-lapse

*Current address: Beckman Research Institute of City of Hope, Duarte, CA 91010, USA.

**Address correspondence to:

Dr. Munehiro Nakata, Department of Applied Biochemistry,

Tokai University, Hiratsuka, Kanagawa 259-1292, Japan.

E-mail: nak@keyaki.cc.u-tokai.ac.jp microscopy to dynamically observe the disappearance of cancer cells from the surface of reconstituted type I collagen gel into the gel (8). Results suggested that the migratory behavior of cancer cells varies depending on their malignancy and that their behavior is unique even when they are members of the same cell population. This previously described method is suited to counting cells disappearing from the gel surface and the Boyden chamber assay is suited to counting cells that reach the bottom of the gel, but neither is suited to observing cells that migrate into the gel.

The present study used type I collagen gel as a model of stromal tissue and it prepared frozen sections of that gel in order to microscopically observe cancer cells both on the gel surface and in the gel. Staining to visualize cells in collagen gels and the effects of several pharmaceuticals on cell migration were also investigated.

\section{Materials and Methods}

\subsection{Cells}

The human breast carcinoma cell line MDA-MB-231 was obtained from the American Type Culture 
Collection (ATCC; Rockville, MD, USA). The cells were maintained in high-glucose Dulbecco's modified Eagle's medium (DMEM; Invitrogen, Carlsbad, CA, USA) containing $10 \%$ fetal calf serum (FCS) supplemented with penicillin-streptomycin and 2 $\mathrm{mM}$ glutamine. Cells were cultured at $37^{\circ} \mathrm{C}$ in a $5 \%$ $\mathrm{CO}_{2}$ atmosphere. The cells were harvested after preincubation in serum-free medium for $24 \mathrm{~h}$ at $37^{\circ} \mathrm{C}$ and resuspended in the same medium before use.

\subsection{Reconstitution of collagen gel}

Reconstituted type I collagen gel was prepared as described before with some modifications (8). Briefly, a solution of bovine skin type I collagen (Koken, Tokyo, Japan) was diluted to $1 \mathrm{mg} / \mathrm{mL}$ in $0.05 \mathrm{M}$ acetic acid and mixed with $10 \times$ DMEM and a reconstitution buffer (1 M Hepes buffer, $\mathrm{pH} 7.4$, containing $\left.10 \mathrm{M} \mathrm{NaHCO}_{3}\right)$ at a ratio of $8: 1: 1(\mathrm{v} / \mathrm{v}$, type I collagen solution/DMEM/reconstitution buffer). Two hundred $\mu \mathrm{L}$ of the solution was added to each well of an 8-well chamber slide (Nalge Nunc, Naperville, IL, USA) and the mixture was then incubated at $37^{\circ} \mathrm{C}$ for $18-20 \mathrm{~h}$ to form mature single-layer gels.

Bilayer type I collagen gels were prepared as follows. A lower gel was first prepared by mixing 100 $\mu \mathrm{L}$ of $0.1 \%$ collagen solution with or without $10 \%$ FCS, DMEM, and reconstitution buffer $(8: 1: 1, \mathrm{v} / \mathrm{v})$ in an 8 -well chamber slide. Two hundred $\mu \mathrm{L}$ of type I collagen gel without FCS (upper gel) formed on the solidified gel containing $8 \%$ FCS, as described earlier.

\subsection{Incubation of cells on reconstituted type I collagen gel and frozen sectioning}

Two hundred and fifty $\mu \mathrm{L}$ of a cell suspension $(4 \times$ $10^{5}$ cells $/ \mathrm{mL}$ ) was loaded onto the reconstituted type I collagen gel in a chamber slide and incubated for $3 \mathrm{~h}$ at $37^{\circ} \mathrm{C}$ in a $5 \% \mathrm{CO}_{2}$ atmosphere. After incubation, the gel surface was rinsed twice with $250 \mu \mathrm{L}$ of phosphatebuffered saline (PBS) and then DMEM containing $0.1 \%$ BSA to remove unbound cells. The gel was subsequently incubated for $18 \mathrm{~h}$ at $37^{\circ} \mathrm{C}$ in a $5 \% \mathrm{CO}_{2}$ atmosphere to allow the cells to migrate into the gel.

To investigate the effects of pharmaceuticals such as the matrix metalloproteinase inhibitor galardin (Cosmo Bio Co., Ltd., Tokyo, Japan), type I collagen gels were prepared in the presence of pharmaceuticals of interest. Cells were pre-incubated with the same concentration of the pharmaceuticals for $30 \mathrm{~min}$ at $37^{\circ} \mathrm{C}$ and then allowed to migrate into the gels.

After removing the medium on the gel surface, the gel was then mounted with an embedding compound (Tissue-Tek O.C.T. Compound; Sakura Finetechnical, Tokyo, Japan) and frozen at $-80^{\circ} \mathrm{C}$. The frozen gel was sliced perpendicular to the gel surface with a cryostat in sections with a thickness of $20 \mu \mathrm{m}$ and the sections were placed on glass slides.

\subsection{Azan staining of frozen collagen gel sections}

Frozen sections of reconstituted type I collagen gel into which cells had migrated were stained using conventional hematoxylin-eosin staining or azan staining that can stain cells and collagen fiber different colors $(9,10)$. For azan staining, the sections were fixed with $20 \%(\mathrm{v} / \mathrm{v})$ formalin solution for $2 \mathrm{~min}$, soaked in xylene, and then successively immersed in $80 \%$ ethanol and $100 \%$ ethanol for $3 \mathrm{~min}$ each. For metachroming, the sections were immersed in $10 \%(\mathrm{w} / \mathrm{v})$ potassium dichromate solution containing $10 \%(\mathrm{w} / \mathrm{v})$ trichloroacetic acid for $10 \mathrm{~min}$ and then stained with $0.1 \%(\mathrm{w} / \mathrm{v})$ azocarmine G (Alfa Aesar, Ward Hill, MA, USA) for $3 \mathrm{~h}$ with occasional observation under an optical microscope. After staining with azocarmine $\mathrm{G}$, the sections were soaked in $0.1 \%$ $(\mathrm{v} / \mathrm{v})$ aniline in $95 \%(\mathrm{v} / \mathrm{v})$ ethanol for a few seconds and then in $0.1 \%(\mathrm{v} / \mathrm{v})$ acetic acid in $95 \%(\mathrm{v} / \mathrm{v})$ ethanol for 1 min. After the sections were rinsed with water, they were immersed in 5\% (w/v) phosphotungstic acid solution for $1 \mathrm{~h}$ and then stained with aniline blue-orange $\mathrm{G}$ solution (Wako Pure Chemical Industries, Osaka, Japan) for $1 \mathrm{~h}$ with occasional observation under an optical microscope. The stained sections were mounted and then observed under a microscope $(\times 200$ or $\times 400$; BX-51, Olympus, Tokyo, Japan).

\subsection{Data processing}

The distance each cell migrated from the gel surface was measured using at least 5 photographs of microscopic visual fields $(\times 200)$ or at least 150 cells. A Mann-Whitney $U$ test was performed with StatMate III software (ATMS, Tokyo, Japan) and a $p$ value less than 0.05 was considered significant.

\section{Results}

\subsection{Enhanced visualization of cells in reconstituted type I collagen gel via azan staining}

While conventional histochemical staining using hematoxylin-eosin is not suited to identifying the gel surface (Figure 1A), azan staining is often used to distinguish collagen fibers in connective tissues $(9,10)$. Azan staining was thus examined to microscopically observe the cancer cell distribution in frozen sections of reconstituted type I collagen gels. As shown in Figure $1 \mathrm{~B}$, azan staining of frozen sections stained cancer cells red and it stained type I collagen fibers blue. This facilitated the microscopic observation of the cancer cell distribution in reconstituted type I collagen gels.

\subsection{Promotion of cell migration by FCS}

Cell migration into reconstituted collagen gels was promoted by using FCS as a chemoattractant. The 


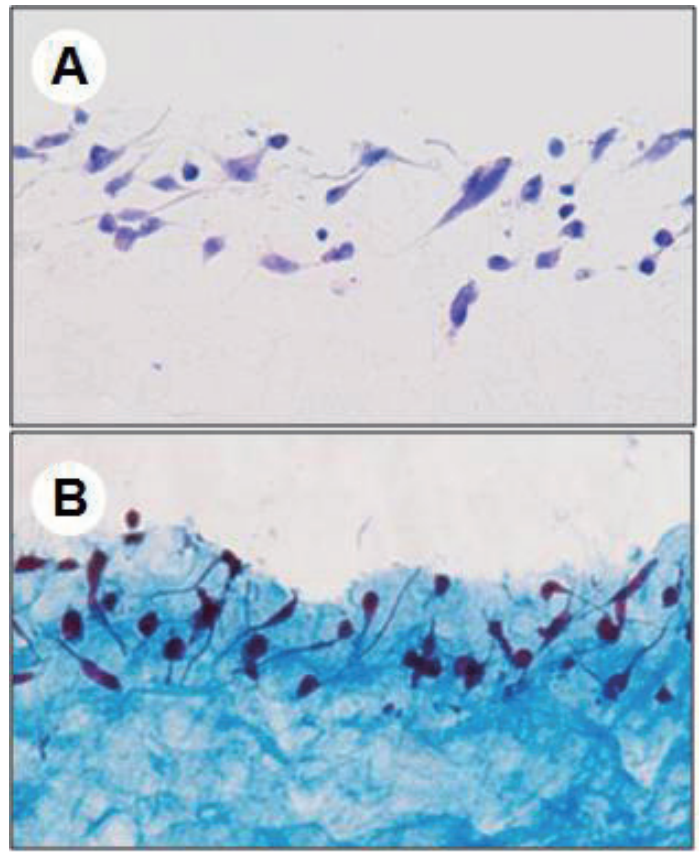

Figure 1. Comparison of microscopic views of gels stained with hematoxylin-eosin and azan staining. MDA-MB-231 cells were allowed to migrate into a type I collagen gel and frozen sections of the gel were stained with hematoxylineosin (A) and azan (B) as described in the Materials and Methods. Original magnification: $\times 200$.
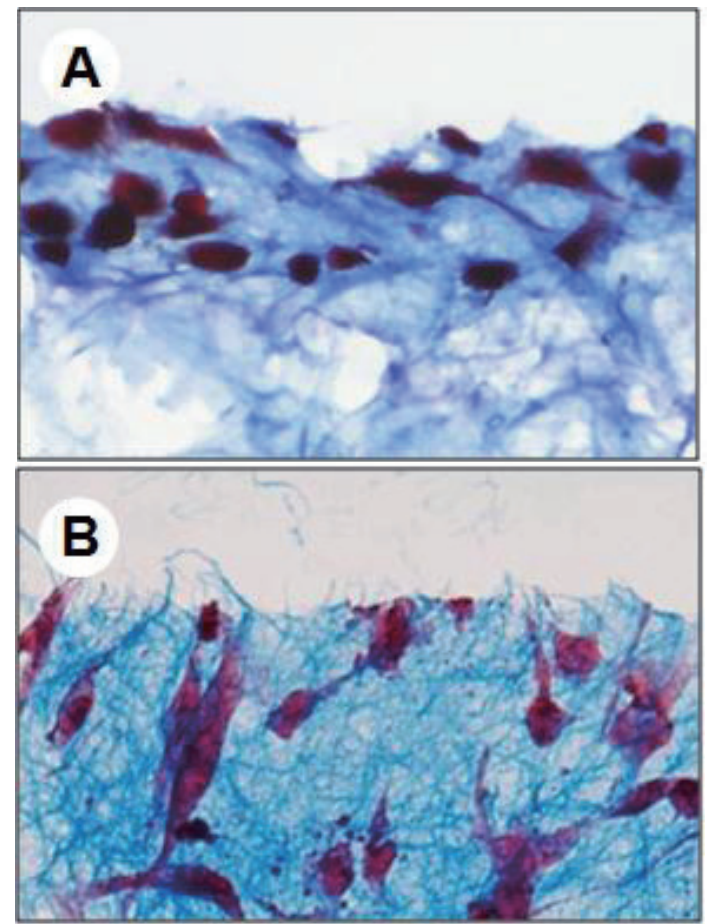

Figure 2. Typical microscopic views of gels where cells were allowed to migrate into the gels in the absence or presence of FCS. MDA-MB-231 cells were allowed to migrate into bilayer type I collagen gels without FCS (A) or with $8 \%$ FCS in the lower gel (B). The frozen sections were stained with azan and observed under a microscope. Original magnification: $\times 400$.

following 2 types of gels were examined: $i$ ) bilayer gels without FCS and ii) bilayer gels with $8 \%$ FCS in the lower gel. As shown in Figure 2, the cell morphology

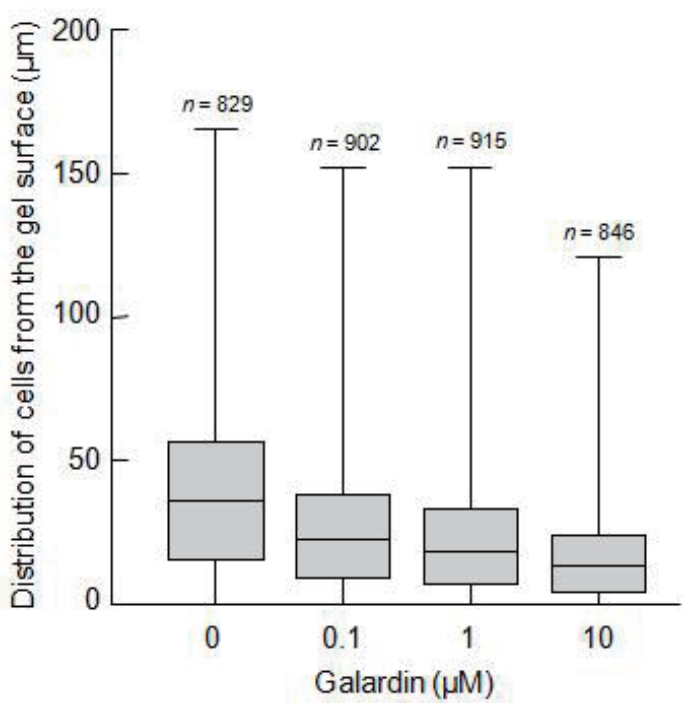

Figure 3. Distribution of cells migrating into type I collagen gels containing various concentrations of galardin. MDA-MB-231 cells were allowed to migrate into bilayer type I collagen gels containing the concentrations of galardin as indicated in the figure and $8 \%$ FCS in upper and lower gels, respectively. The frozen sections were stained with azan and then the cell distribution was observed microscopically. For data processing, the distance from the gel surface was taken into account only for cells distributed in the gel but not for cells remaining on the gel surface.

changed dramatically and cell migration was promoted in the latter gel system using FCS. In the absence of FCS, $24.1 \%$ of cells remained on the gel surface and cells that migrated into the gel were distributed at a median distance of $17.5 \mu \mathrm{m}(8.9,21.1 ; n=216)$ from the gel surface (data not shown). In contrast, the number of cells remaining on the gel surface decreased $(11.9 \%)$ in the presence of FCS and the distance of migration from the gel surface increased to a median distance of $26.4 \mu \mathrm{m}(15.8,40.7 ; n=193)$ (data not shown).

\subsection{Cell migration in the presence of galardin}

During invasion, cancer cells produce MMPs to digest extracellular collagens (4). Galardin is a synthetic MMP inhibitor with a broad spectrum of activity against various MMP species $(11,12)$. Figure 3 shows the distribution of the distance that cells migrated from the gel surface in the presence of lower gel containing $8 \%$ FCS for untreated cells and cells treated with various concentrations of galardin. The proportion of cells remaining on the gel surface was $2.9 \pm 0.9 \%$ in the absence of galardin. This proportion increased to $6.8 \pm 0.6 \%$ in the presence of 0.1 $\mu \mathrm{M}$ of galardin, to $7.7 \pm 1.3 \%$ in the presence of $1 \mu \mathrm{M}$ of galardin, and to $12.4 \pm 2.0 \%$ in the presence of $10 \mu \mathrm{M}$ of galardin (data not shown). Some cells migrated a relatively long distance in the presence of galardin but the median distance that cells migrated from the gel surface was significantly shorter than in the absence of galardin: 63.0 $\pm 2.1 \%$ in $0.1 \mu \mathrm{M}$ of galardin, $57.1 \pm 3.7 \%$ in $1 \mu \mathrm{M}$ of galardin, and $45.7 \pm 1.2 \%$ in $10 \mu \mathrm{M}$ of galardin $(p<0.001)$. 


\section{Discussion}

The present study devised a novel approach to assess the invasive ability of cancer cells. Cells of the human breast carcinoma cell line MDA-MB-231 served as model cancer cells and reconstituted type I collagen gel served as a model of stromal tissue. Cancer cells migrating into the gel were satisfactorily observed using a combination of FCS to promote cell migration on the bilayer gel (Figure 2B) and azan staining of frozen sections of the gel (Figure 1B). This approach allows the observation of cells on the gel surface and cells migrating into the gel. Invasive ability can be assessed based on the proportion of cells migrating into the gel and the distance cells have migrated from the gel surface. The distance of migration can also be used to assessment the invasive ability of an individual cell. Additionally, this approach is suited to observing the promotion of cell migration by chemoattractants (Figure 2 ) and to assessing the inhibition of cell migration by pharmaceuticals such as galardin. Galardin is a known as MMP inhibitor (11-13) and is reported to prevent invasion and metastasis $(14,15)$ (Figure 3).

Recently, various quantitative methods of assessing cell migration and invasion have been reported $(8,14$ 19). Some of these methods facilitate the fluorescenceassisted quantification or real-time observation of migrating cells. The present method involves observation of frozen sections, and this approach would facilitate immunocytochemistry to detect molecular species expressed on the cell surface or released around cells.

Cancer cells invading stromal tissues have routes of migration that involves various matrix-degrading metalloproteinases, such as MMPs, and cell adhesion molecules, such as integrins (2,4,20-22). Since most of the previous studies of the migratory ability of cancer cells have mainly dealt with cell populations but not individual cells, a detailed molecular basis for individual characteristics of migratory ability needed to be elucidated. A previous study involving the real-time observation of cancer cell invasion noted that individual cells invaded at different times (8). The present study found that some cells remained on the gel surface while others migrated into the gel a considerable distance from the gel surface (Figure 3), suggesting that migratory ability exhibits individual characteristics. The present approach could be used to examine the individual characteristics of that ability in combination with immunocytochemistry.

Carcinoma cell migration and invasion play a role in the initial phase of metastasis, in which cells migrate from a tumor to invade normal stromal tissues and then the circulatory system. Therefore, cells may migrate a long distance in stromal tissues. The present study using a model of stromal tissues suggested that some cells migrated a relatively long distance (Figure
3). In addition, the MMP inhibitor galardin was not very effective at inhibiting the long distance that cells migrated at the concentrations used in this study. Pharmaceuticals that can inhibit this cell migration step would help to prevent metastasis.

In conclusion, the present study devised an approach to observe cancer cell migration into reconstituted type I collagen gel via a combination of frozen sectioning and azan staining. This approach is a useful way to assess the ability of individual cancer cells to migrate and to evaluate how effective certain pharmaceuticals are at inhibiting the first step of invasion process.

\section{Acknowledgements}

The authors wish to thank Dr. Keiko Sakai for her valuable input. The authors received a grant-in-aid for research and education from the Tokai University School of Engineering and technical support from the Department of Cell Biology and Histology, Education and Research Support Center, Tokai University School of Medicine.

\section{References}

1. Hagedorn EJ, Sherwood DR. Cell invasion through basement membrane: the anchor cell breaches the barrier. Curr Opin Cell Biol. 2011; 23:589-596.

2. Valastyan S, Weinberg RA. Tumor metastasis: molecular insights and evolving paradigms. Cell. 2011; 147:275292.

3. Liotta LA, Thorgeirsson UP, Garbisa S. Role of collagenases in tumor cell invasion. Cancer Metastasis Rev. 1982; 1:277-288.

4. Ennis BW, Matrisian LM. Matrix degrading metalloproteinases. J Neurooncol. 1994; 18:105-109.

5. Boyden SV. The chemotaxis effect of mixtures of antibody and antigen on polymorphonuclear leukocytes. J Exp Med. 1962; 115:453-466.

6. Simon N, Noël A, Foidart JM. Evaluation of in vitro reconstituted basement membrane assay to assess the invasiveness of tumor cells. Invasion Metastasis. 1992; 12:156-167.

7. Albini A, Benelli R, Noonan DM, Brigati C. The "chemoinvasion assay": A tool to study tumor and endothelial cell invasion of basement membranes. Int J Dev Biol. 2004; 48:563-571.

8. Sakai K, Kurokawa T, Furui Y, Kuronuma Y, Sekiguchi M, Ando J, Inagaki Y, Tang W, Nakata M, FujitaYamaguchi Y. Invasion of carcinoma cells into reconstituted type I collagen gels: Visual real-time analysis by time-lapse microscopy. BioSci Trends. 2011; 5:10-16.

9. Fujii T, Hirabayashi Y. Histochemical studies of glycosaminoglycans in developing periodontal ligaments of ICR mice. Anat Rec. 1999; 254:465-473.

10. van Griensven M, Zeichen J, Tschernig T, Seekamp A, Pape HC. A modified method to culture human osteoblasts from bone tissue specimens using fibrin glue. Exp Toxicol Pathol. 2002; 54:25-29.

11. Grobelny D, Poncz L, Galardy RE. Inhibition of 
human skin fibroblast collagenase, thermolysin, and Pseudomonas aeruginosa elastase by peptide hydroxamic acids. Biochemistry. 1992; 31:7152-7154

12. Augé F, Hornebeck W, Laronze JY. A novel strategy for designing specific gelatinase A inhibitors: potential use to control tumor progression. Crit Rev Oncol Hematol. 2004; 49:277-282.

13. Zhang J, Li X, Zhu H, Wang Q, Feng J, Mou J, Li Y, Fang $\mathrm{H}, \mathrm{Xu} \mathrm{W}$. Design, synthesis, and primary activity evaluation of pyrrolidine derivatives as matrix metalloproteinase inhibitors. Drug Discov Ther. 2010; 4:5-12.

14. Almholt K, Juncker-Jensen A, Laerum OD, Danø K, Johnsen M, Lund LR, Rømer J. Metastasis is strongly reduced by the matrix metalloproteinase inhibitor galardin in the MMTV-PymT transgenic breast cancer model. Mol Cancer Ther. 2008; 7:2758-2767.

15. Blacher S, Jost M, Melen-Lamalle L, Lund LR, Romer J, Foidart JM, Noël A. Quantification of in vivo tumor invasion and vascularization by computerized image analysis. Microvasc Res. 2008; 75:169-178.

16. Duong HS, Le AD, Zhang Q, Messadi DV. A novel 3-dimensional culture system as an in vitro model for studying oral cancer cell invasion. Int J Exp Pathol.
$2005 ; 86: 365-374$.

17. Weaver AM. Invadopodia: specialized cell structures for cancer invasion. Clin Exp Metastasis. 2006; 23:97-105.

18. Liu T, Li C, Li H, Zeng S, Qin J, Lin B. A microfluidic device for characterizing the invasion of cancer cells in 3-D matrix. Electrophoresis. 2009; 30:4285-4291.

19. Selvendiran K, Ahmed S, Dayton A, Ravi Y, Kuppusamy ML, Bratasz A, Rivera BK, Kálai T, Hideg K, Kuppusamy P. HO-3867, a synthetic compound, inhibits the migration and invasion of ovarian carcinoma cells through downregulation of fatty acid synthase and focal adhesion kinase. Mol Cancer Res. 2010; 8:1188-1197.

20. Nicolson GL. Tumor and host molecules important in the organ preference of metastasis. Semin Cancer Biol. 1991; 2:143-154.

21. Jacquemet G, Humphries MJ, Caswell PT. Role of adhesion receptor trafficking in $3 \mathrm{D}$ cell migration. Curr Opin Cell Biol. 2013; 25:627-632.

22. Canel M, Serrels A, Frame MC, Brunton VG. E-cadherin-integrin crosstalk in cancer invasion and metastasis. J Cell Sci. 2013; 126:393-401.

(Received August 20, 2014; Accepted August 25, 2014) 